Matsika, Emmanuel, O’Neill, Conor, Grasso, Marzio and De Iorio, Antonio (2018) Selection and ranking of the main beam geometry of a freight wagon for lightweighting. Proceedings of the Institution of Mechanical Engineers, Part F: Journal of Rail and Rapid Transit, 232(2), pp. 495-513. Copyright ( 2018 SAGE Publications. DOI: 10.1177/0954409716677075. 


\title{
SELECTION AND RANKING OF THE MAIN BEAM GEOMETRY OF A FREIGHT WAGON FOR LIGHTWEIGHTING
}

\author{
Emmanuel Matsika, Conor O'Neill \\ NewRail, School of Mechanical and Systems Engineering \\ Newcastle University, UK \\ Marzio Grasso \\ School of Engineering and Technology, University of Hertfordshire \\ College Lane Campus UK \\ Antonio De lorio \\ Polytechnic School of Basic Sciences, Federico II University, Naples, Italy
}

\begin{abstract}
Traditional freight wagons employ I-beam sections as the main load bearing structures. The primary loads they carry are vertical (from loading units) and axial (from train traction and buffers). Ease of manufacturing has played an important role in selection of the I-beam for this role. However, with lightweighting increasingly becoming an important design objective an evaluation needs to be done to assess if there are other existing or new section profiles (geometry) that would carry the same operational loads but are lighter.
\end{abstract}

This paper presents an evaluation of 24 section profiles for their ability take freight wagon operational loads. The profiles are divided into two categories, namely; "conventional made by wagon manufacturers (including the I-beam)" and "pre-fabricated" sections. For ranking purposes, the primary design objectives, or Key Performance Indicators (KPIs) were bending stress, associated deflection, and buckling load. Subsequently this was treated as a multi-criteria decision making process. The loading conditions were applied as prescribed by the EU standard EN $12663-$ 2.

To carry out structural analysis, Finite Element Analysis (FEA) was implemented using ANSYS software. To determine the validity of the FEA results, correlation analysis was done with respect to beam theory. Parameters considered were: maximum stress, deflection, second moment of area, thickness, bending stiffness and flexural rigidity. The paper discusses the impreciseness related to the use of beam theory since the local stiffness of the beam is neglected leading to an inaccurate estimation of the buckling load and the vertical displacement. Even more complicated can be the estimation of the maximum stress to be used for comparison when features such as spotwelds are present. The nominal stress values computed by means of Navier equation leads to 
an inaccurate value of the stress since it neglects the variations in the local stiffness, which can lead to an increase in the bending stress values.

The main objective of the paper is the applicability of particular cross section to the railway field with the aim of lightweighting the main structure. Compound sections commonly adopted in civil applications have been investigated to understand the stiffness and strength under railway service loads. The common approach reported in literature so far makes use either of the beam theory [1] or topological FE approach [2] to identify the optimised shape under the action of the simplified loading conditions. Although the previous approaches seem to be more general, the assumptions made affect the optimization process since the stress state differs from that attained under service load in the real structure. In the present paper the use of complex shape cross sections and detailed finite element models allow to take in account the real behaviour in terms of stiffness distribution and local stress effects due to manufacturing features like welds. The structural assessment carried out with the detailed models allow the proper comparison among the considered sections.

Analysis of the results showed that 3 out of the 24 section profiles have the highest potential to be fitted as the main load bearing beams for freight wagons, with the pre-fabricated $Z$ section being the optimum of the three.

\section{Key words}

Intermodal freight wagon; section profiles/geometry; bulking; bending; deflection; multi-criteria decision making; lightweighting

\subsection{BACKGROUND}

Generally speaking, the optimisation of any engineering component requires investigation of the materials and sections properties [3]. Following the trend of past decades in development of structural optimisation algorithms for weight and member sizing, many methods have emerged to achieve these goals [4]. Shape and topology optimisation are concerned with finding the optimal shape and topology of a structure by the iterative process based on structural response analysis and sensitivity calculation [5]. It is possible to find in literature very complex approaches such as the multi-resolution and multi-scale topology optimisation which makes use of wavelet transforms [6]. Other simpler, but having a wider application, are based on topology optimisation techniques proposing a unified treatment of several parameters [7]. Due to the complexity of some of these 
methods, it has been necessary to develop multi-objective optimisation computer programs to deal with the increasing numbers of requirements to be included in the optimisation process [8].

In most cases either the material properties or the shape of the sections are given and the optimisation process deals with the selection of the complementary parameters that satisfy the objective function [9]. The objective function is usually represented by the minimisation or maximisation of a given function and it depends on several parameters called control variables. The optimisation process usually requires the identification of more than one objective function and more often they are in conflict each other [10]. The subsequent multi-objective optimisation process requires that the best match be found between the available profiles and the requirements of the design. The optimum solution is found by means of the performance index, which is a group of properties that governs some aspects of the performance of a component [11]. When multiple non-commensurable and conflicting criteria are present, the selection problem can be solved by adopting multi-criteria decision-making (MCDM) methods. The MCDM methods have the capabilities of assessing the criteria weights and ranking the alternatives from the best to the worst [12]. In order to rank the different solutions and chose the best among them, the definition of performance matrices (which can be a combination of materials properties as well as a combination of performances in different areas such as manufacturability and costs) is needed. It is clear that for identifying the best solution ordering and ranking is necessary. In particular the ranking process depends on the availability of assessment criteria [13].

When assessing the feasibility of a certain solution it is also important to address the uncertainty related to the materials properties, geometry, and loading conditions of the structure in reality. In this view methods such as the Robust Topology Optimisation [14] have become increasingly important since in them the variability of certain parameters is taken into account to identify the optimum solution. In addition to the uncertainty it is important in addressing the suitability of a certain design taking into account the manufacturing process [15]. More often the best solution is the one for which the costs can be reduced having at the same time a structural response which is among those in accordance with the performance index even if it is not the best [11]. In the last few years, solutions such as the cold-formed beams have been extensively used for application in different areas of civil building due to the optimal combination of performance and costs of such kind of structure [16]. In particular, cold-formed steel members have become very popular in the construction of metal wall and roof systems in industrial and commercial buildings due to their 
high strength to weight ratio $[17,18]$. Moreover, it is possible to reduce the costs related to the manufacturing process since they can be used to fit different designs. However, these beams are prone to local buckling due to the thin-walled nature of the sections. The local and global buckling to which such kind of sections can undergo, requires a full analysis of the structural behaviour in order to properly understand the applicability to various design configurations [19-21].

The potential applicability of the aforementioned ideas can push forward the innovation of the transport systems making them more competitive. Moreover, the need for innovative high performance vehicles for the next generation of freight trains is inevitable. The process of achieving that is complex due to the fact that you need to optimise the shape of the cross-section as well as chose a high performance material from among those available, which are about 160000 $[1,22]$.

On the basis of the aforementioned considerations, the identification of the best solution in terms of the shape of the cross section for the central beams of a railway wagon requires the identification of as much information as it is possible in terms of costs, manufacturability and structural response. In this view, the development of a 3D model of intermodal freight wagon central beams (with which it is possible to identify the structural response in terms of bending stiffness and strength as well as local and/or global buckling) has been implemented. The model and structural response provide the useful information needed for the identification of the assessment criteria and thus the ranking assessment in the multi-objective scheme adopted in this paper to optimise the central beam of the wagon.

\subsection{INTRODUCTION}

Globally, the design of freight railway vehicles is increasingly giving significant attention to lightweighting [1, 2, 22-24]. This has been driven in the main by consideration for reduced emissions and impact on the infrastructure. In addition, the potential introduction of mixed running of freight and passenger vehicles requires that the former has similar dynamic characteristics as the latter. This includes high acceleration and deceleration as well as higher top speeds. Such improved performance could be achieved simply by increasing the locomotive power. However, this would increase both emissions and track wear. Lightweighting therefore provides a viable means to attain higher dynamic performance with either the same or reduced locomotive power. 
The measures of attaining lightweight constructions can be separated into three types as listed below [25].

The first type of lightweight construction is to replace materials of high specific weight with lower density materials without reducing stiffness and durability. Common lightweight materials are, for example, metals such as aluminium, magnesium, high strengthened steels or various types of unreinforced and reinforced composites. Secondly, structural lightweight construction implies that load-carrying elements and exterior attachments are optimised in their (geometrical) design so as to reduce their weight without any loss in rigidity or functionality. Another way of realising lightweight constructions is to optimise the production process. In the automotive industry, the reduction of spot welds should reduce the body weight when replaced by new joining techniques such as laser welding or manufacturing processes such as hydroforming.

Using the automotive industry as an example, steel makes up over $50 \%$ of road vehicles [21]. Application of high strength steels (HSSs) as opposed to mild steel has achieved high mass reduction. With freight wagons made up of over $90 \%$ steel structure, the HSSs present a great potential for significant lightweighting.

Described in this paper is research conducted as part of the EC Framework 7 project called SPECTRUM [23]. The aim of the research was to develop rail freight services to match seamlessly with customer supply chains. The project determined how to effectively integrate low density, high value, time sensitive freight services with existing passenger services without detriment to either service type, taking into consideration operational, technological and logistics requirements. The main task was therefore to design a lightweight intermodal freight wagon, with respect to existing over-specified heavier wagons, in order to achieve higher dynamic performance. This paper presents the applied research conducted in achieving lightweighting of the wagon through systematically selection of optimal section profiles of the superstructure.

\subsection{DESIGN SCOPE}

As mentioned in the previous section, the research in this paper relates to a real-life project to a lightweight intermodal freight wagon. Table 1 shows specific constraints and factors that guided the design, specifically selection of structural geometry for lightweighting purposes. The most commonly used compound sections in design of freight wagon frames are based on I and C 
sections profiles [26]. Some, however, are based on the $Z$ section. See Table 2 and Figure 1 for the illustrations.

Table 1: Design Constraints/Factors

\begin{tabular}{|c|c|c|}
\hline Constraint & Details & Remarks \\
\hline \multirow[t]{2}{*}{ Space } & $\begin{array}{l}\text { Accommodate power convertor on each semi wagon: } \\
\text { Length }=2000 \mathrm{~mm} \\
\text { Width }=800 \mathrm{~mm} \\
\text { Height }=600 \mathrm{~mm} \\
\text { Weight }=500 \mathrm{~kg}\end{array}$ & $\begin{array}{l}\text { - For dynamic stability, centrally locate the } 0.5 \mathrm{t} \\
\text { power unit. } \\
\text { - PC should be accessible for maintenance. Noting } \\
\text { that the unit has a high reliability. } \\
\text { - Allow for adequate ground clearance (noting that } \\
\text { ground to the wagon top is } 1155 \mathrm{~mm} \text { taking } \\
\text { account of bounce motion). }\end{array}$ \\
\hline & $\begin{array}{l}\text { Accommodate the InnovaTrain horizontal transhipment } \\
\text { technology. }\end{array}$ & $\begin{array}{l}\text { - Five adaptor frames per platform (each weighing } \\
430 \mathrm{~kg} \text { ). Accommodate } 20 / 40 / 45 \text { foot containers } \\
\text { and } 7.45 \mathrm{~m} \text { swap body. } \\
\text { - Inserting a separate adaptor frames. }\end{array}$ \\
\hline $\begin{array}{l}\text { Dynamic } \\
\text { performance }\end{array}$ & $\begin{array}{l}\text { To minimise the tare weight, it was recommended that } \\
\text { the centre of gravity should be shifted from the } \\
\text { centre bogie towards the outer bogies. }\end{array}$ & $\begin{array}{l}\text { - Power convertor located towards outer bogies. } \\
\text { - The transhipment adaptor frames are a } \\
\text { constraint. }\end{array}$ \\
\hline
\end{tabular}

Table 2: Conventional/Ordinary Longitudinal Beam Section Profiles

\begin{tabular}{|c|c|}
\hline $\begin{array}{l}\text { Type of Cross } \\
\text { Sectional Profile }\end{array}$ & $\begin{array}{l}\text { Profile } \\
\text { Sketch }\end{array}$ \\
\hline Closed Box sect & \\
\hline Open Box Sectio & \\
\hline
\end{tabular}

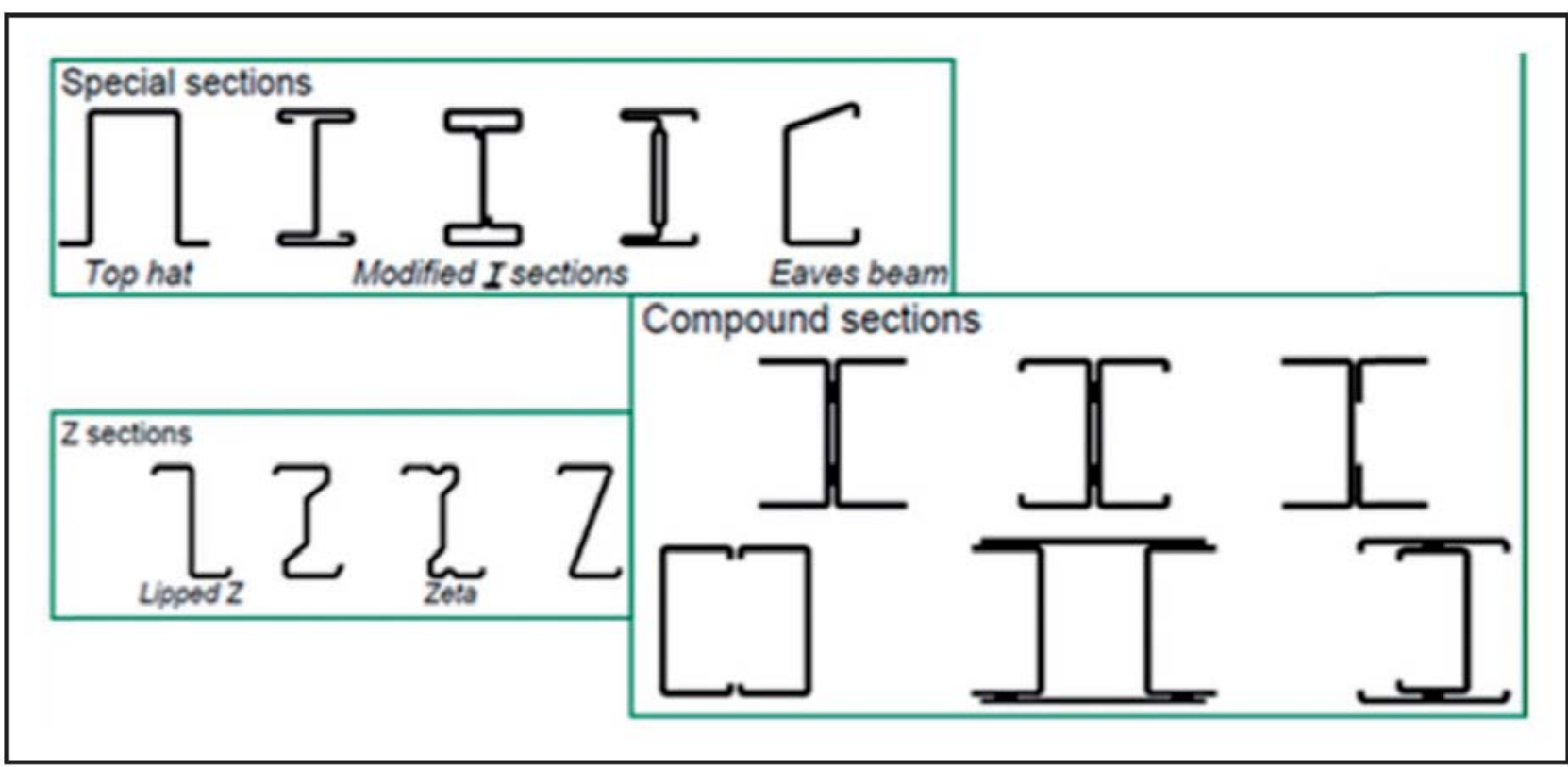

Figure 1: Prefabricated Sections 
Most intermodal freight wagons running in Europe consist of a platform that is a welded steel structure. The main supporting elements are ridged and side rails. The sill is usually made in the form of I-beams with variable cross section. The traditional design of wagon is a platform with a frame in the form of a beam with a carrier equiresistant (uniform load) sill (Fig. 2). The beam has variable-section, with weaker sections in the ends (where the bogie is connected), and stronger in the central part where the bending moment is highest. The frame is a welded steel structure; the basic elements are the carriers and side sill. Table 3 shows the design characteristics of a typical wagon.

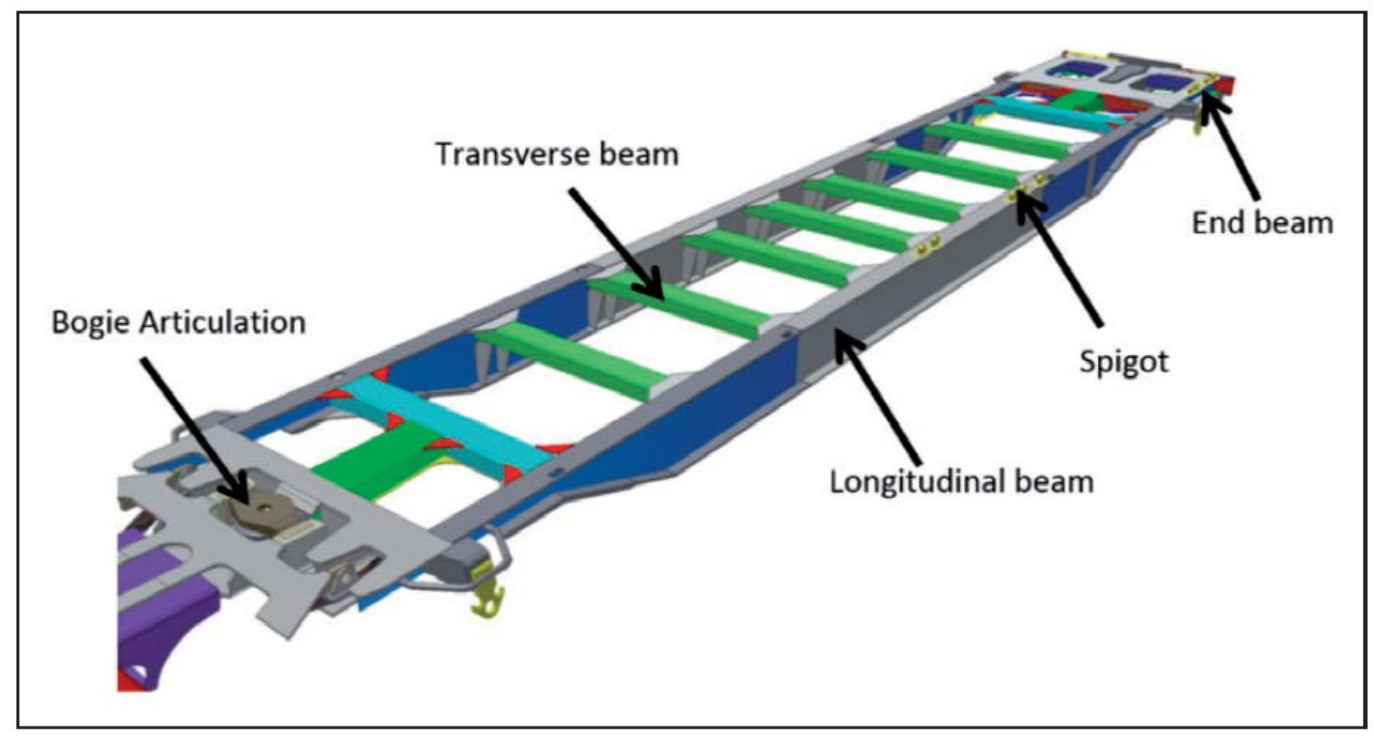

Figure 2: Standard Flat Wagon Design [22]

Table 3: Design Characteristics of a Typical Flat Wagon

\begin{tabular}{|c|c|}
\hline Design aspect & Justification \\
\hline $\begin{array}{l}\text { Two I-beams on outer } \\
\text { sides of the wagon }\end{array}$ & $\begin{array}{l}\text { - To provide for multi-platform } \\
\text { concept (fixing stations and } \\
\text { sidewalls for box wagons). } \\
\text { - Improve torsional stiffness }\end{array}$ \\
\hline $\begin{array}{l}\text { Varying section } \\
\text { in the } x-y \text { plane }\end{array}$ & $\begin{array}{l}\text { Variable section allows for } \\
\text { uniform bending strength } \\
\text { along the beam (lower } \\
\text { bending moment on the } \\
\text { ends). } \\
\text { - Allows for lowering of the } \\
\text { loading platform, thus } \\
\text { accommodating high cube } \\
\text { containers (critical in coun- } \\
\text { tries where the loading gauge } \\
\text { is low). }\end{array}$ \\
\hline I-beams & $\begin{array}{l}\text { - To increase bending strength } \\
\text { in the longitudinal plane. }\end{array}$ \\
\hline Permanent joints & $\begin{array}{l}\text { - Improve rigidity } \\
\text { - Minimise vibrations }\end{array}$ \\
\hline UIC Spigots & $\begin{array}{l}\text { - Improve operational } \\
\text { efficiency }\end{array}$ \\
\hline
\end{tabular}


As part of structural section optimisation, 24 profiles were considered as detailed in Table 2 and Figure 1. By applying both quantitative and qualitative criteria in a three-stage selection process, one profile was chosen as preferable to meet the lightweighting design objective. Details of the process are presented under methodology (Section 4.0).

\subsection{METHODOLOGY}

The iterative design process of the SPECTRUM intermodal wagon is shown in Figure 3. While the main process was running vertically from initial CAD design to final CAD model, other factors influence key inputs that defined the scope and constraints of the design. These included required dynamic performance, fitting of electrical systems and the type of cargo transhipment technology applied.

Two categories of section profiles were considered. The first constitutes those that are fabricated by wagon manufacturers from raw material ('manufacturer fabricated') and the second being those pre-fabricated by (usually) the steel manufacturers through cold or hot rolling or forming. Table 4 shows the advantages and disadvantages of the two.

Nine sections predominantly used in Europe and USA, and fifteen pre-fabricated sections were considered. In order to determine the most suitable profile, a three-stage procedure (as indicated in the flow chart in Figure 4 ) was applied.

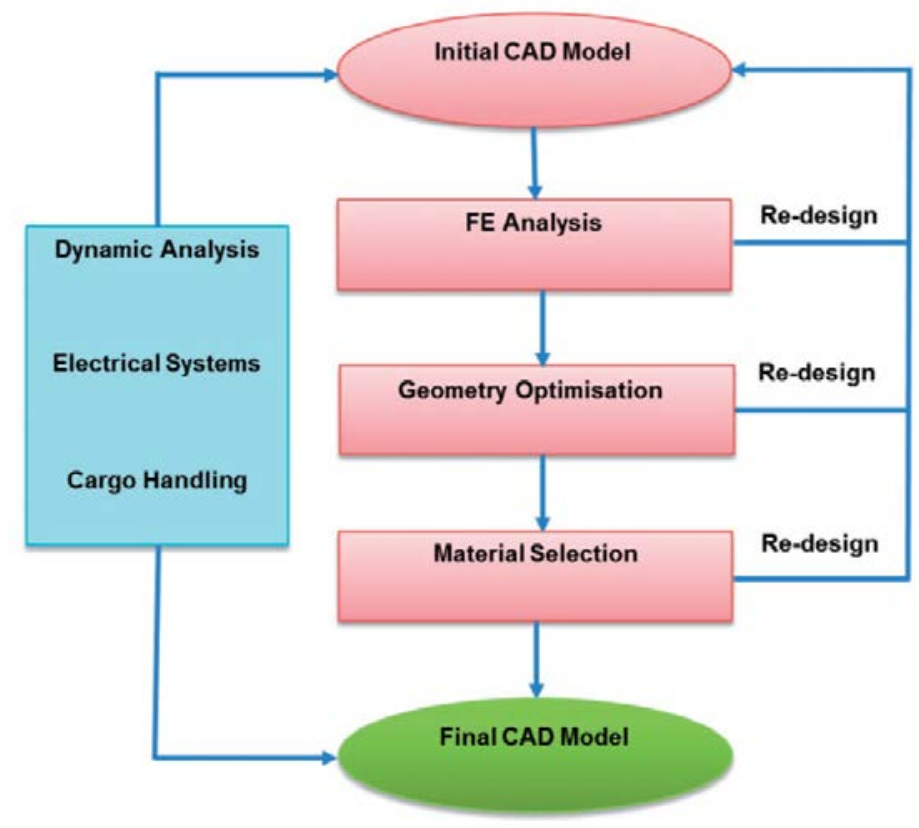

Figure 3: SPECTRUM Wagon Design Process 
Table 4: Advantages and Disadvantages of Manufacturer vs Pre-fabricated Wagon Sections

\begin{tabular}{lll}
\hline Section type & Advantages & Disadvantages \\
\hline Wagon manufacturer fabricated & High customisation & - Long manufacturing process \\
& & - Labour intensive \\
Pre-fabricated & Difficult to customise & - Leaves much waste (in terms of off cuts) \\
& & - Less labour intensive \\
& & - Limit on thickness of the raw material \\
\hline
\end{tabular}

Preliminary selection stage: The initial 24 profiles were assessed on their potential for general engineering application for rail wagon.

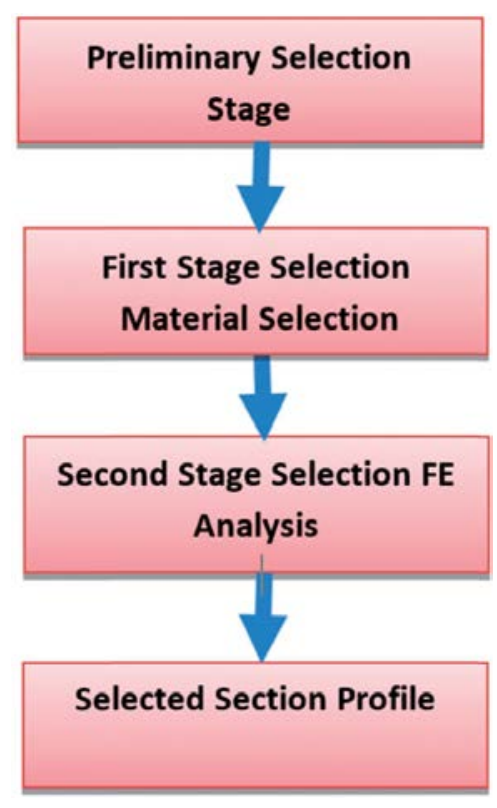

Figure 4: Selection process of section profiles

First Stage Selection: 14 section profiles that went through the preliminary stage were analysed for the following Key Performance Indicators (KPIs):

- Maximum bending stress

- Maximum deflection

- Buckling load

The indicators applied were based on the most critical loading conditions (bending and axial loading). Both EC standards and general design of freight wagons show that these are two most critical loading conditions for longitudinal beams. The steel industry applies these as a measure of cross section resistance to failure. 
The first load is bending in the longitudinal vertical plane and the other being buffer (compressive) loading from which the tendency to buckle is inferred. To this effect, the indicators (or KPIs) applied were bending stress (MPa) and deflection $(\mathrm{mm})$, and buckling load $(\mathrm{N})$. It should be noted that a section profile is deemed to perform better with reducing values of stress and deflection. Conversely, it is deemed to perform better with increasing values of buckling load.

Since lightweighting is the main design objective function, all the sections considered weighed $215 \mathrm{~kg} / \mathrm{m}$. On that basis the better performing sections were those that could provide a good balance of being able to withstand bending loads and compressive loads as determined by the indicators explained in the previous section.

Second Stage Selection: Three top section profiles were subjected to assessment using four KPIs:

- Dynamic performance

- Manufacturability

- Number of parts

- Formability of parts

- Section assemblability

- Ease of integration into the wagon structure

- Cost (implied through manufacturing and transportation costs)

- Environmental impact (e.g. waste generated)

Since the SPECTRUM wagon is concerned with lightweighting and ensuring that there is space for auxiliary items such as power convertor, the two objective functions chosen for the first stage selection procedure were constant mass per unit length of each section $(\mathrm{kg} / \mathrm{m})$, with each occupying the same volume. Figure 5 shows the cross sectional area of the first design (I-beam). This was the benchmark (or reference) section. All the other sections had to fit into the $770 \mathrm{~mm} \mathrm{x}$ $700 \mathrm{~mm}$ space, each having a length of $7535 \mathrm{~mm}$ which was the length of the widest portion of the I-beams. An iterative procedure was applied to for that each section had a thickness to ensure a constant mass per unit length. 


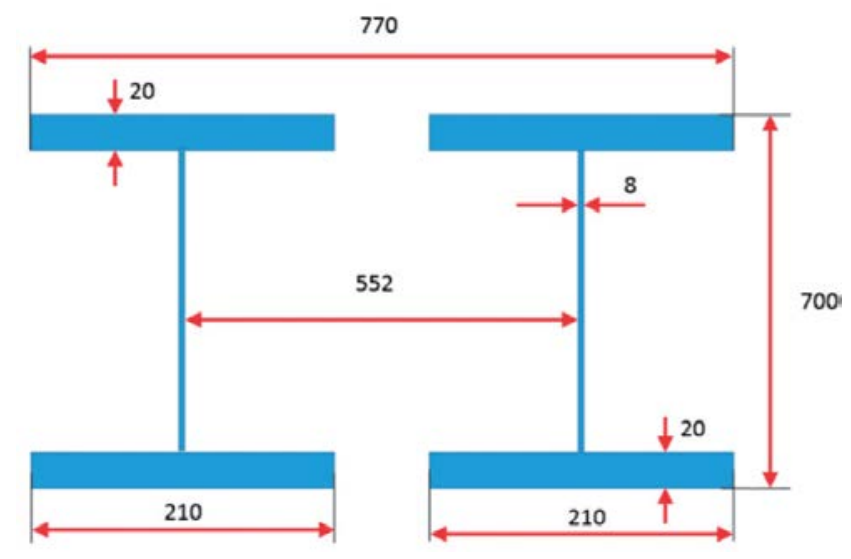

Figure 5: Cross Section of the Longitudinal Beams for the Benchmark Wagon Design

Due to the complexity of some of the section profiles, FEA was applied using ANSYS to conduct structural analysis.

\subsection{STRUCTURAL ANALYSIS USING FEA}

The numerical simulations carried out during the first stage covered determination of the axial buckling loads and evaluation of the bending behaviour in terms of maximum bending stress and maximum deflection.

The numerical analysis has been conducted considering the central longitudinal beam of the current design of the original SPECTRUM wagon, and replacing the original I-beams, which are located symmetrically with respect to the longitudinal plane, with the 13 alternative sections profiles chosen for the first selection stage. Shown in Figure 6 are the details of the section profiles.

For the sake of comparison, the characteristic dimensions of each section have been chosen so that the total space occupied by cross sections as well as the total masses are equal to those of the I-beam's, which saves as reference. The two constraints were imposed because the two design objectives were lightweighting and space optimisation. For the cross section of the I-beam, refer to Figure 5.

The common modelling approach in structural optimization is to implement an FE model of the structure using beam elements. Although this approach is widely used, there are several limitations as the real distribution of the stiffness over the component and the details related to particular features are not included. To overcome the limitations, in this paper the mid-surfaces of the beams have been generated in the CAD software. These surfaces have been meshed using 
shell elements. In particular, the shell element with linear shape functions, which are already implemented in the ANSYS library as SHELL 181, have been used. The welds have been modelled using rigid connections. For the ordinary sections the elements by which the section is composed are connected for the whole length along the longitudinal direction, thus the fillet has been modelled by coupling the corresponding nodes using constraint equations (Fig. 7-A). For the prefabricated sections, the connection between the different elements of the section is realised using spotwelds having a diameter equal to $10 \mathrm{~mm}$ and located at a distance $\delta=100 \mathrm{~mm}$ between each other (Fig. 7-B). Moreover, the spotwelds are located symmetrically with respect to the symmetry planes of the cross section (Fig. 7-C).

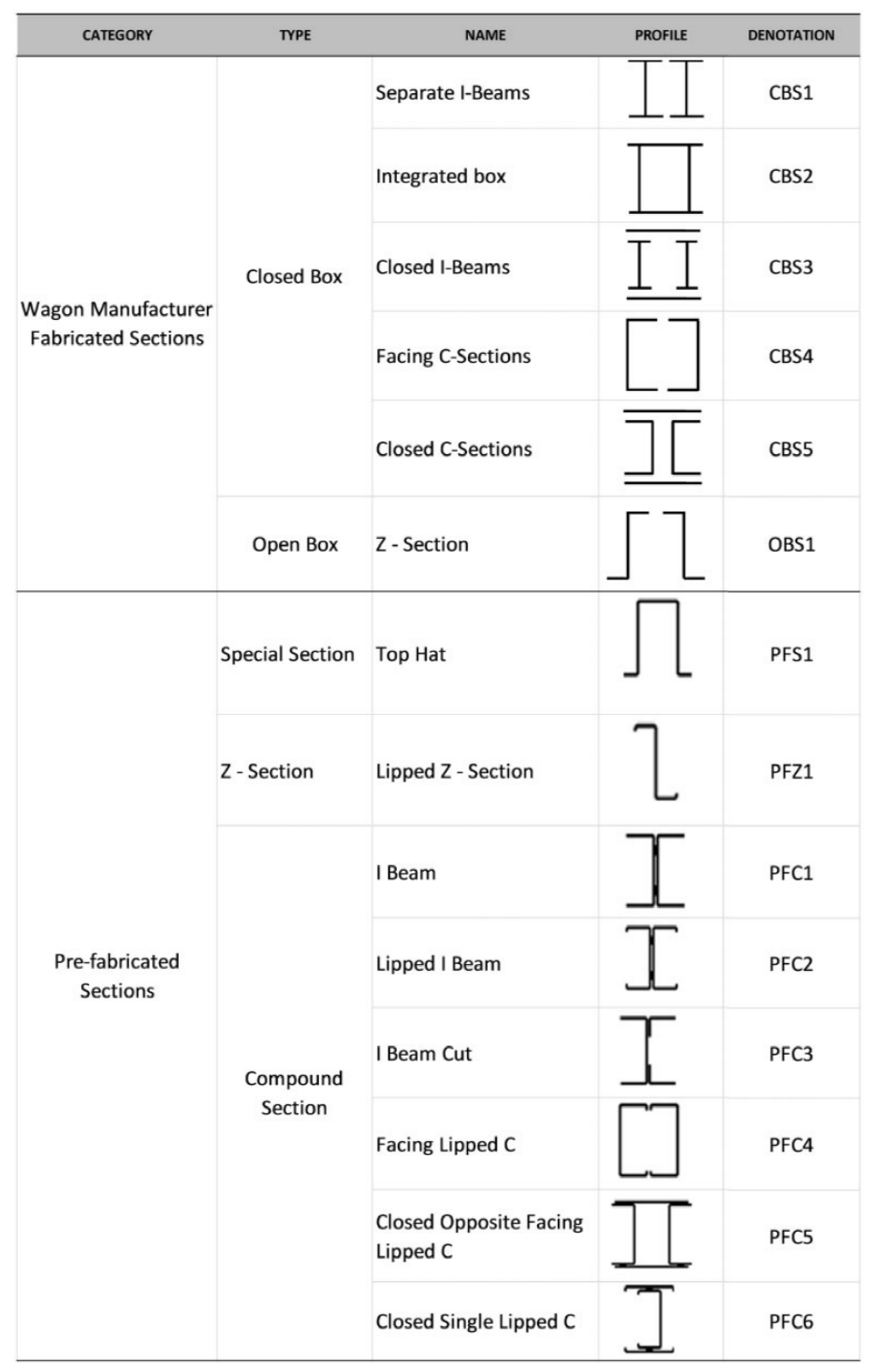

Figure 6: List of the 14 sections 

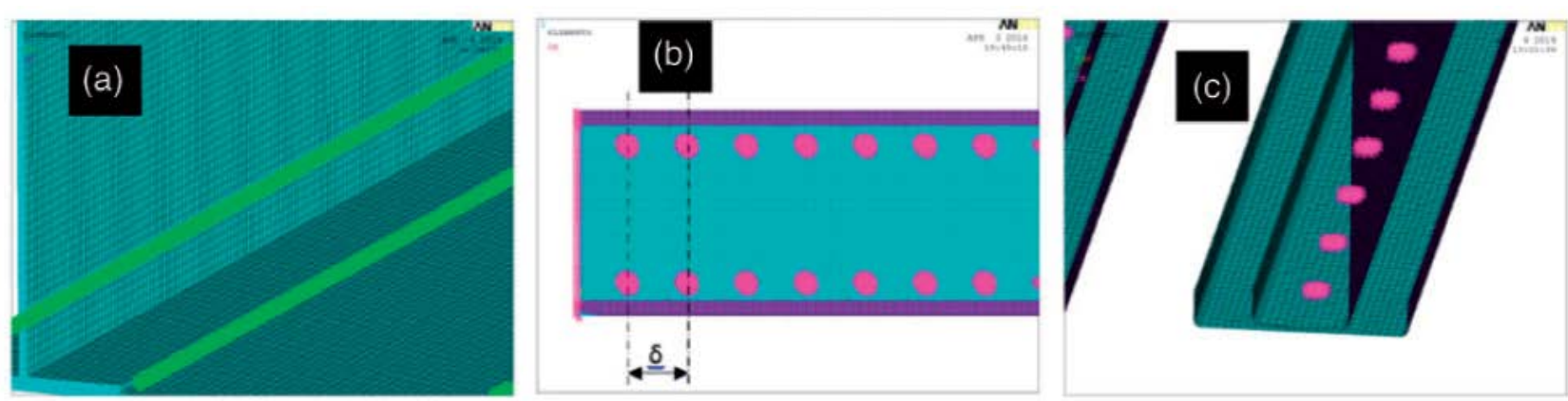

Figure 7: Details of the rigid connections adopted for the continuous spot welds.

The material chosen for all sections is S355J2 steel. It is modelled as linear elastic, having defined Young's Modulus E = $205 \mathrm{GPa}$ and poisson's ratio v $=0.29$.

The boundary conditions adopted for the numerical analysis have been chosen in accordance with the service conditions of the wagon. Figure 8 indicates the way in which the loading was applied. The tendency to undergo buckling under the action of the axial load has been evaluated, since one of the most important loading conditions is represented by the compressive load created at the buffers level. Bending behaviour has been studied since the loading units would exert a bending load in the vertical direction. The loading conditions were applied as prescribed by the EU standard EN 12663 - 2 [27]. The maximum stress and maximum deflection on the mid-plane of the wagon are two of the parameters to be considered in the design of the wagon.

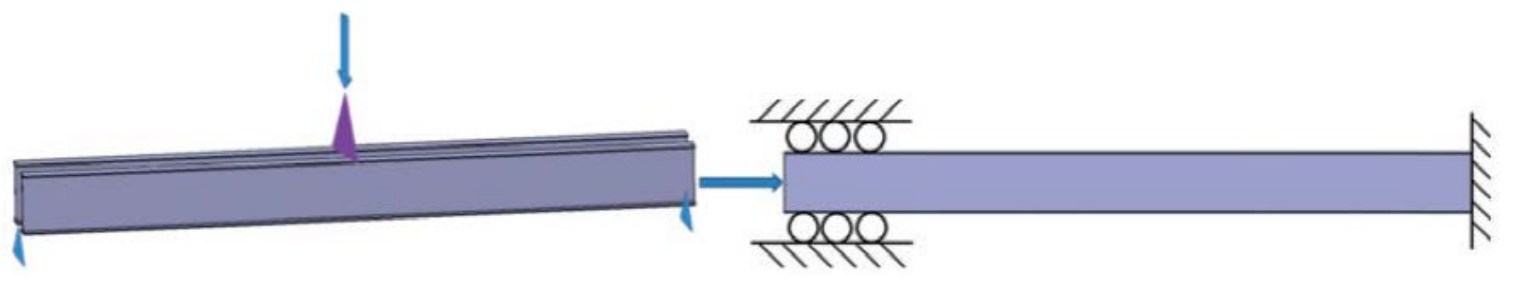

Figure 8 - Boundary conditions used for the numerical analysis.

In particular, the loading and constraint conditions adopted are:

For the buckling analysis: on one end all degrees of freedom (DoFs) were constrained. On the other end (where the axial load is applied), all DoFs were constrained except for the axial displacement.

For the bending analysis: two hinges at the two ends and a rigid region in the mid plane by which the vertical load equal to $22.5 \mathrm{t}$ (the nominal axle load for freight wagons) has been applied. The master node of the rigid region has been used to constrain the displacement along the longitudinal axis of the beams. 
The 'first buckling load' has been used for comparison. The maximum bending stress has been evaluated in the midsection whilst the maximum vertical displacement, due to the different deformed configurations, has been measured at the master node of the rigid region used to apply the vertical load.

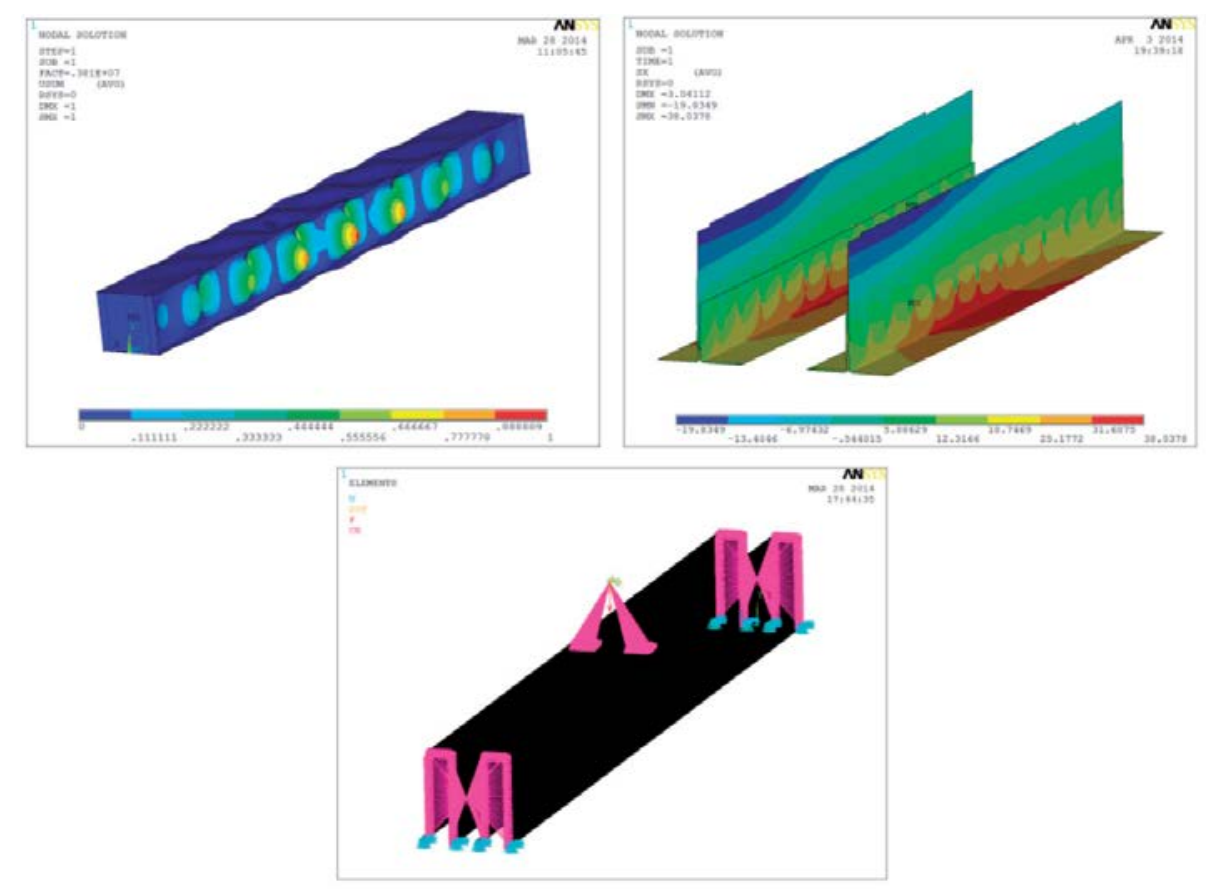

Figure 9: Deformed buckling configuration - details of the longitudinal stress and master node used to evaluate the vertical displacement.

After FEA of the 14 sections, four sections were chosen for further selection process based on their good performance. Further numerical simulations on the four sections were carried out in order to identify the optimal section. The criteria for the second set of analysis is based on the structural response of the beams under the action of the dynamic loads produced by the vertical and the transverse accelerations induced in service.

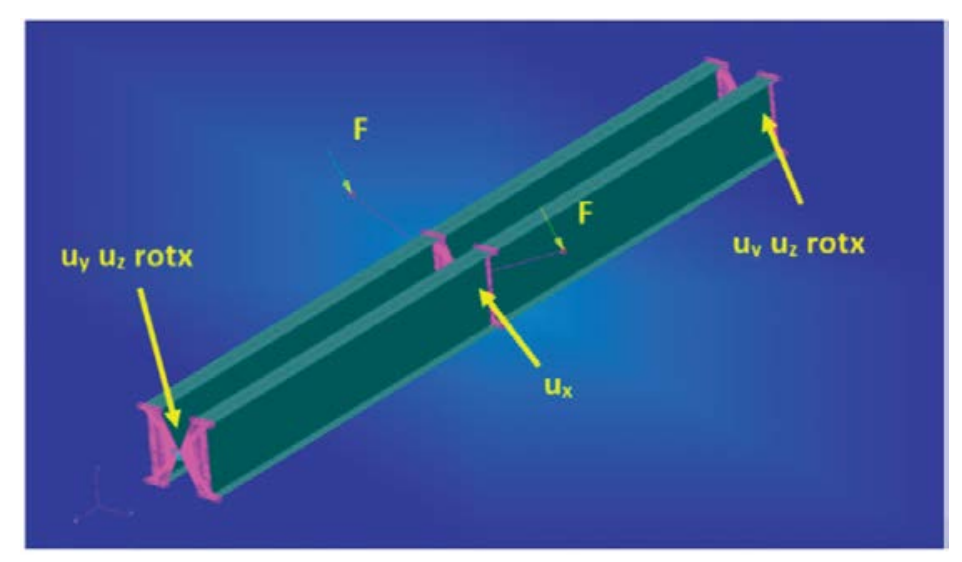

Figure 10: Boundary Conditions adopted for the second series of simulations. 
In order to better simulate the structural response of the beams under the real service conditions, two concentrated masses at the spigots and in the midsection were introduced. These masses have been rigidly connected to the nodes of the mid-cross-section by means of coupling equations. On the nodes of the concentrated masses the vertical and the lateral accelerations prescribed by the Standard EN 14363:2005 [28] and equal to $5 \mathrm{~m} / \mathrm{s} 2$ and $3 \mathrm{~m} / \mathrm{s} 2$ respectively have been applied. The forces corresponding to the aforementioned accelerations produce torsion and bending, which are transmitted to the constraints at the two ends, to which vertical and lateral displacements are associated. The values of these have been used to compare the performance of the four sections under evaluation for choosing the optimal section.

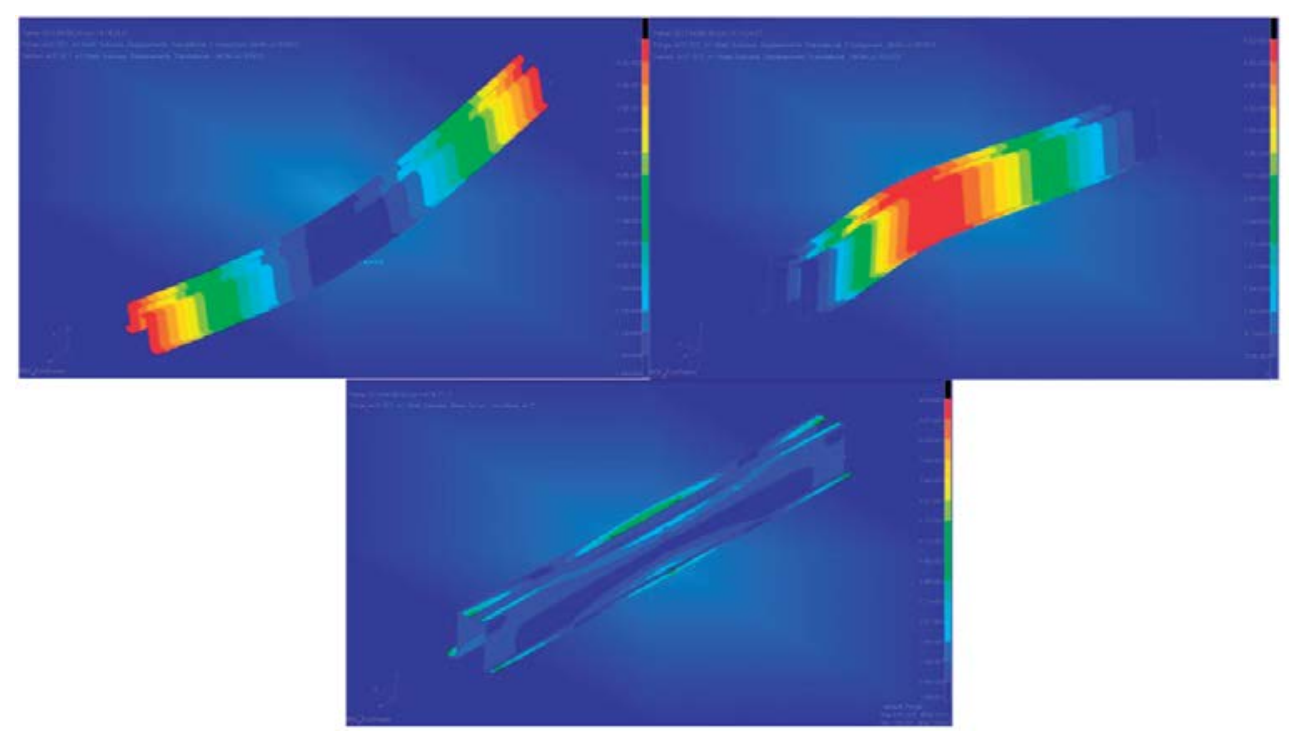

Figure 11 - Vertical, lateral and Von-Mises stress for the Z section.

\subsection{RESULTS}

\subsection{First Stage Selection}

The results in Table 5 show that the only KPI that is barely met is deflection, and it is therefore given highest level of importance when ranking the section profiles. Buckling is given the lowest level of importance in the ranking process because it has been met based on the prescribed loading of 1,200 kN from the EN 12663:-2 2010 [27]. This conclusion is further supported by the fact that the bucking load for all the 14 section profiles ranged from $1577.2 \mathrm{~N}$ to $8009.9 \mathrm{~N}$ (See Figure 12). Therefore, all the profiles would meet the buffer loading requirement. Subsequently, buckling is not considered further in the ranking process. The varying importance of the indicators is further strengthened by the following: 
Bending is applied in daily operations due to the weight of loading units (containers and swap bodies).

With the SPECTRUM wagon designed for block wagon loads, the wagons would not be subjected to buffer loading on a regular basis.

The results from buckling loads indicate that out of the 14 section profiles considered; none would fail under the buffer loading of 1,200 kN for category F-II freight vehicles according to EN 12663:2:2010 [27].

From this point onwards, only two KPIs are considered. A graphical method is applied to determine the best section using the optimal trade-off to minimise both the bending stress and deflection objective functions.

Table 5: Summary results from FE Analysis of Initial Design of the SPECTRUM Wagon

\begin{tabular}{llc}
\hline Parameter & Value & Comment \\
\hline $\begin{array}{l}\text { Maximum bending } \\
\text { stress in main } \\
\text { I-beam }\end{array}$ & $149 \mathrm{MPa}$ & $\begin{array}{c}\text { Less than material } \\
\text { yield strength of } \\
355 \mathrm{MPa}\end{array}$ \\
$\begin{array}{c}\text { Maximum deflection of } \\
\text { the main I-beam }\end{array}$ & $41.3 \mathrm{~mm}$ & $\begin{array}{c}\text { Close to } 45 \mathrm{~mm} \\
\text { allowable }\end{array}$ \\
$\begin{array}{c}\text { Minimum buckling load } \\
\text { of the wagon }\end{array}$ & $1200 \mathrm{kN}$ & $\begin{array}{c}\text { No buckling observed } \\
\text { in l-beams }\end{array}$ \\
\hline
\end{tabular}

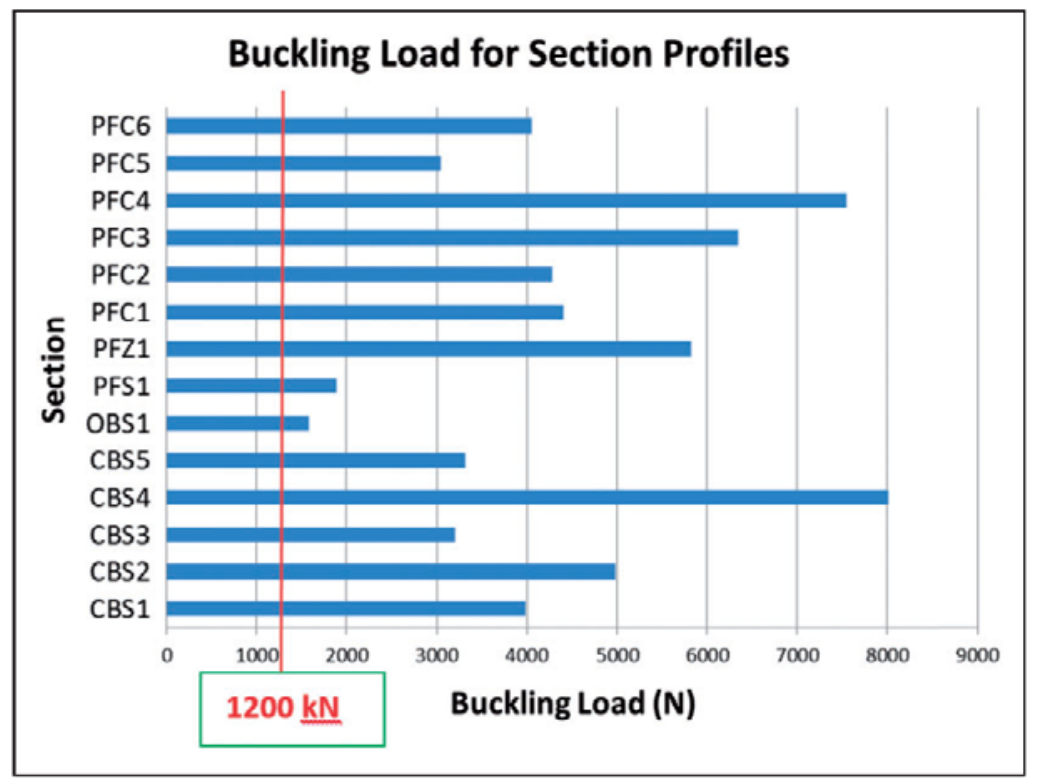

Figure 12: Buckling loads for the 14 Section Profiles 
The methodology applied to determine which section profile to choose is based on that from [29], which optimises a design with conflicting objectives; in this case minimising both the stress and deflection. From Figure 13, the top Cluster A (CBS4, OBS1, PFS1, PFC2, PFC4 and PFC6) in the top right corner is disregarded on the basis of having high stress and deflection levels. Although CBS3 (Cluster B) has one of the least stress levels, it is disregarded on the basis of having a relatively high deflection compared to the preferred section profiles. Cluster C (PFZ1, PFC3, CBS5, CBS1, PFC5, CBS2 and PFC1), which has the best performing sections, is further analysed as amplified in Figure 14. Two sections are emerging as having the best performance because they are closest to the trade-off surface: PFZ1 in terms of lowest deflection (and therefore high stiffness) and CBS5 with the lowest stress level. However, each has a downside with PFZ1 having a relatively higher stress level, while CBS5 has a relatively higher deflection. A compromise is seen in PFC3 which falls near the middle of the two, but is far from the trade-off surface. When considering section profiles to take forward for further analysis, these three are selected. This means that those in the top right corner (CBS1, CBS2, PFC1 and PFC5) are disregarded for further consideration. However, since CBS1 is the I-beam section (the reference), it is taken forward for analysis together with the top three, merely for comparison with current practice. As mentioned earlier, the analysis carried so far indicated that deflection is the most important (or critical) KPI. The lipped Z section was therefore the most preferred section due to its low deflection (high stiffness) characteristic. This is followed by PFC3, despite it exhibiting higher stress level than CBS5. Its preference to CBS5 is supported by the fact that it has a lower deflection. In addition, it also performs better in terms of buckling resistance by a factor of nearly 2 (6339.1 N for PFC3 against $3319.9 \mathrm{~N}$ for CBS5). Considering the aforesaid, the ranking of the three selected section profiles is summarised in Table 6.

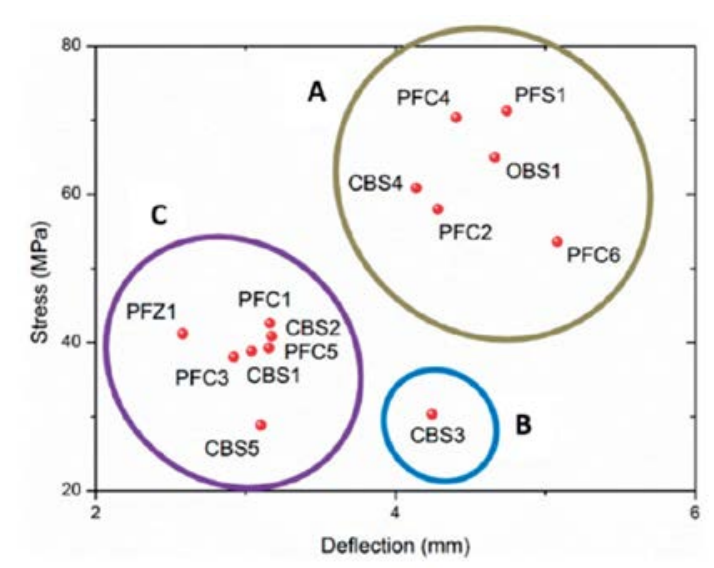

Figure 13: Bending stress against deflection for the 14 Section Profiles 


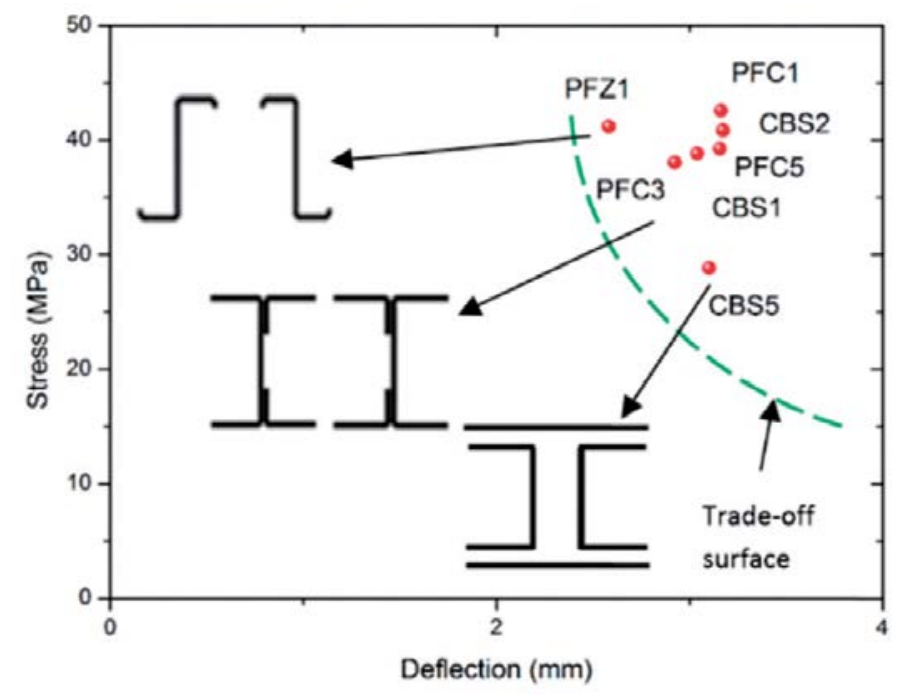

Figure 14: Bending stress against deflection for the 7 considered Section Profiles

Table 6: Ranking of the Best Three Section Profiles

\begin{tabular}{|c|c|c|c|c|c|}
\hline \multirow{2}{*}{$\begin{array}{l}\text { Section } \\
\text { Profile }\end{array}$} & \multirow{2}{*}{$\begin{array}{l}\text { Section } \\
\text { Sketch }\end{array}$} & \multicolumn{3}{|c|}{ Manufacturability } & \multirow[b]{2}{*}{ Environmental Impact } \\
\hline & & $\begin{array}{l}\text { Number } \\
\text { of Parts }\end{array}$ & Part Processing & Section Assembly & \\
\hline $\begin{array}{l}\text { Lipped Z- } \\
\text { section } \\
\text { (PFZ1) }\end{array}$ & & 1 & $\begin{array}{l}\text { - Forming } \\
\text { - Cutting }\end{array}$ & N/A & $\begin{array}{l}\text { - Pre-fabricated at steel factory } \\
\text { - Transported pre-fabricated } \\
\text { - Minimal waste/off cuts at wagon } \\
\text { factory } \\
\text { - Reduced labour requirements }\end{array}$ \\
\hline $\begin{array}{l}\text { I Beam Cut } \\
\text { (PFC3) }\end{array}$ & & 3 & $\begin{array}{l}\text { - Forming } \\
\text { - Cutting }\end{array}$ & - Spot welding & $\begin{array}{l}\text { - Pre-fabricated at steel factory } \\
\text { - Transported pre-fabricated }\end{array}$ \\
\hline $\begin{array}{l}\text { Closed C } \\
\text { Sections } \\
\text { (CBS5) }\end{array}$ & & 4 & $\begin{array}{l}\text { - Forming } \\
\text { - Cutting }\end{array}$ & $\begin{array}{l}\text { - Arc welding } \\
\text { - Integrated box }\end{array}$ & $\begin{array}{l}\text { - Fabricated at wagon factory } \\
\text { - Transported as raw materials } \\
\text { - Increase labour at factory }\end{array}$ \\
\hline $\begin{array}{l}\text { Separate I- } \\
\text { Beams } \\
\text { (CBS1) - } \\
\text { benchmark }\end{array}$ & & 3 & - Cutting & - Arc welding & $\begin{array}{l}\text { - Fabricated at wagon factory } \\
\text { - Transported as raw materials } \\
\text { - Increase labour at factory }\end{array}$ \\
\hline
\end{tabular}

The top two most preferred sections are pre-fabricated ones. This entails that pre-fabricated sections present a better potential for lightweighting than the ordinary (conventional) sections.

\subsection{Second (Final) Section of Section Profile}

In Section 6.1, three section profiles were chosen out of fourteen following the analysis of their capability to withstand bending and buckling loads. A further more detailed selection process is applied in this section (stage three in Section 4.0). For the purposes of comparison with the baseline section, the traditional I beam (CBS1) is included in the analyses. 
Dynamic performance results are summarised in the Figure 15. Although the closed section CBS5 had best performance in terms of displacement and stress, it does not consider material that needed to be removed to make holes to accommodate the power convertor in the centre of the wagon (see Table 1).
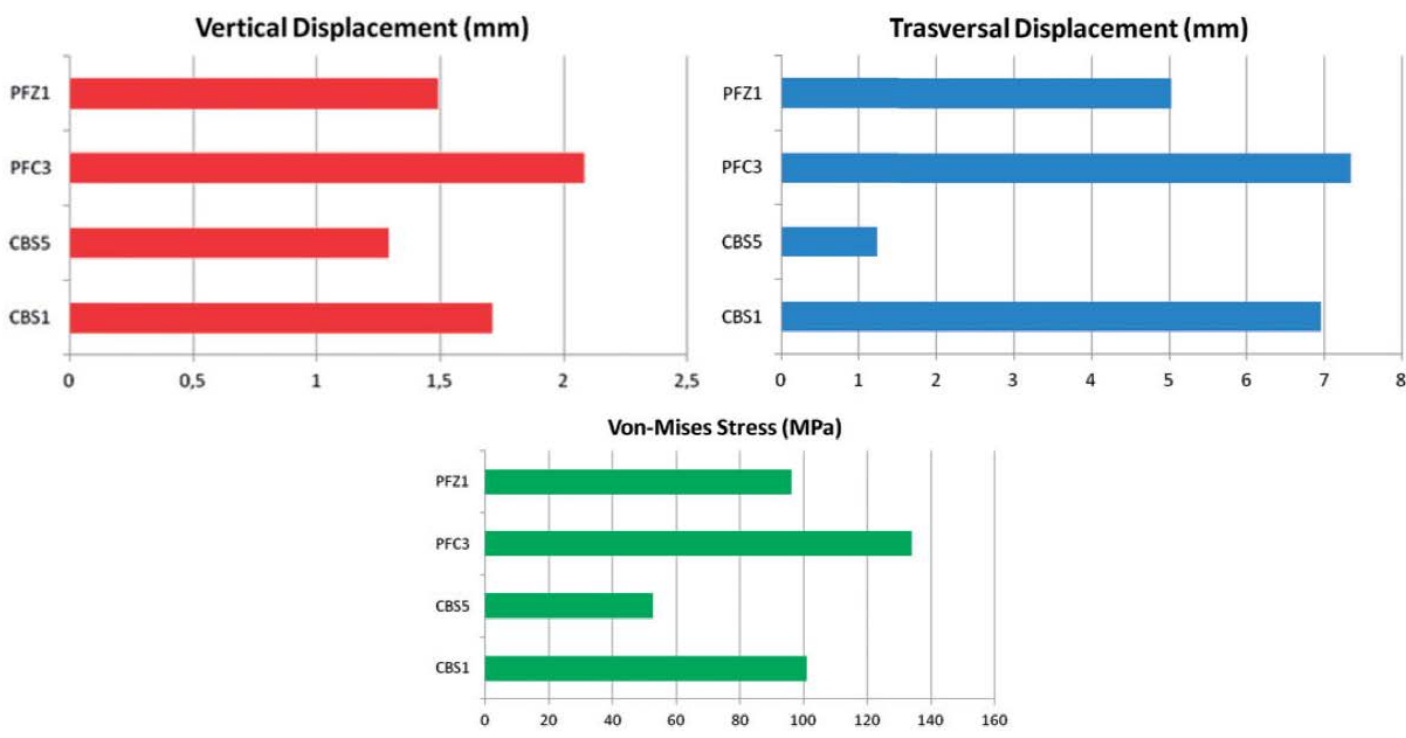

Figure 15: Dynamic analysis results

The key characteristics of each profile are presented in Table 7 related to manufacturability, cost and potential environmental impact.

Table 7: Final Assessment of Section Profiles

\begin{tabular}{|c|c|c|c|c|c|c|c|c|}
\hline \multirow[b]{2}{*}{ Section profile } & \multirow[b]{2}{*}{$\begin{array}{l}\text { Dynamic } \\
\text { performance }\end{array}$} & \multicolumn{4}{|c|}{ Manufacturability } & \multirow[b]{2}{*}{ Cost } & \multirow[b]{2}{*}{$\begin{array}{l}\text { Environmental } \\
\text { impact }\end{array}$} & \multirow[b]{2}{*}{ Score } \\
\hline & & $\begin{array}{l}\text { No. of } \\
\text { parts }\end{array}$ & Formability & $\begin{array}{l}\text { Section } \\
\text { assemblability }\end{array}$ & Integration & & & \\
\hline Lipped Z-section (PFZI) & 4 & 5 & 4 & 5 & 3 & 4 & 4 & 29 \\
\hline I-beam cut (PFC3) & 2 & 2 & 3 & 3 & 3 & 3 & 2 & 18 \\
\hline Closed C-sections (CBS5) & 5 & 1 & 3 & 2 & 4 & 2 & I & 18 \\
\hline $\begin{array}{l}\text { Separate I-beams } \\
\qquad(\text { CBSI }) \text { - benchmark }\end{array}$ & 3 & 2 & 5 & 3 & 4 & 3 & I & 21 \\
\hline
\end{tabular}

A Likert scale ( 1 to 5 ) is applied to determine how favourable a section profile is for each KPI. In this case, a score of 1 represents least favourable, while 5 represents most favourable. Table 8 presents a summary of the assessment. For comparison purposes, the section profile CBS1 that was applied in the original (first iteration) design has been included as a benchmark (or reference). With all KPI considered, the $Z$ section profile presents the overall best option for lightweighting under the design constraints of the SPECTRUM Wagon. 


\subsection{Discussion of the results}

In the previous sections, the results obtained by means of the FE models implemented in ANSYS have been discussed in order to make a comparison among them and select the cross section suitable for the particular application. In this section, the same results obtained with the numerical simulations will be analysed in order to identify useful correlations and general considerations. With this purpose graphs and response surfaces have been obtained. The correlation between the maximum stress and the deflection (Figure 16) can be fitted with a straight line which has a different slope with respect to the beam theory because the deflection computed with FE analysis take in count local effects, such as rotation of the cross sections and variation in the stiffness over the beam, that are neglected in Saint Venant's principle.

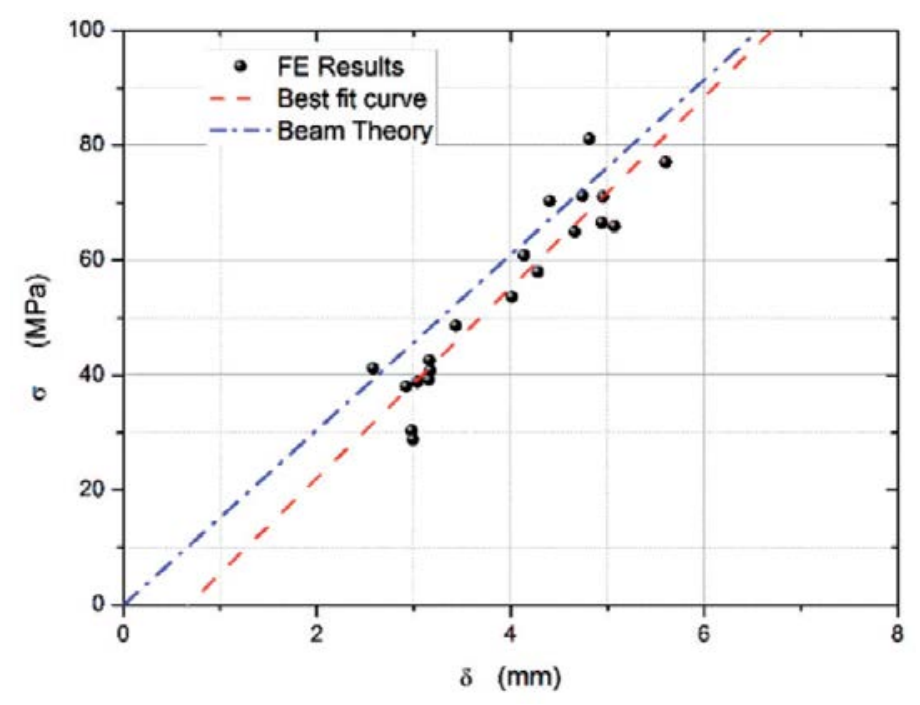

Figure 16: Correlation between maximum stress and deflection

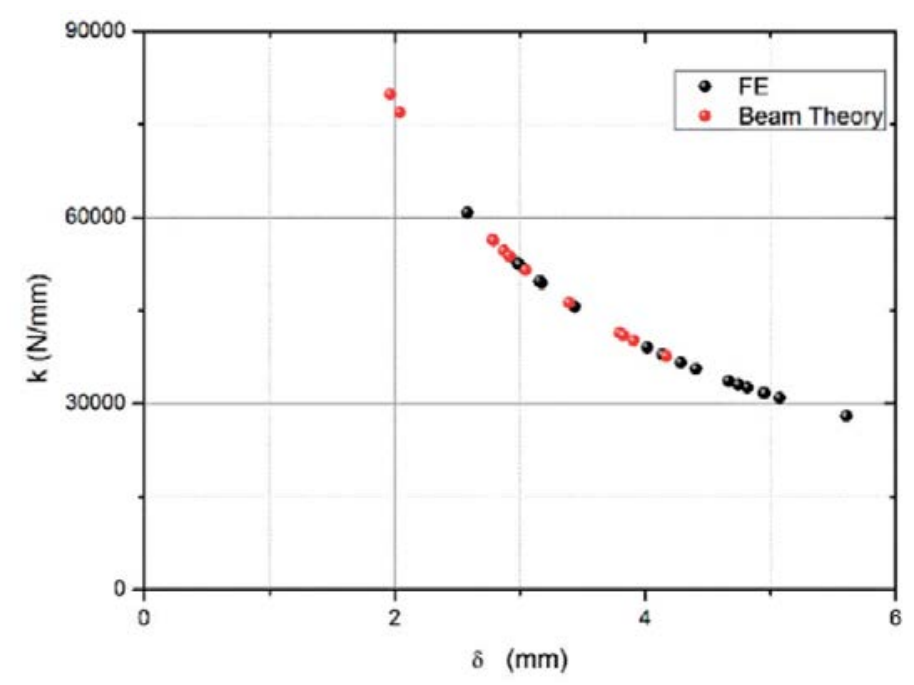

Figure 17: Correlation between bending stiffness and deflection 
However Figure 17 shows that the bending stiffness values with respect to the vertical displacement computed using the beam theory and those from the FE analysis are in perfect agreement. This is because the stiffness is a global property which is not affected by the local behaviour of the beam.

In the analysis of the buckling load for the different cross sections most of them undergo local buckling. The analytical approach that can be used to estimate the local buckling load for the beam is related to flexural stiffness of the plate. Considering part of the beam as a plate, the stiffness $D$ is identified as graphically represented in Figure 18. The beams with the higher values of the flexural rigidity are OBS1 PFC4 PFZ1 and CBS4 all of them having the thickness greater than $12.75 \mathrm{~mm}$. It can be seen that for the aforementioned beams the buckling is global except for the CBS4 for which the buckling is local because it has a closed cross section which leads to a high value of the second moment of area and thus it is more prone to a local buckling.

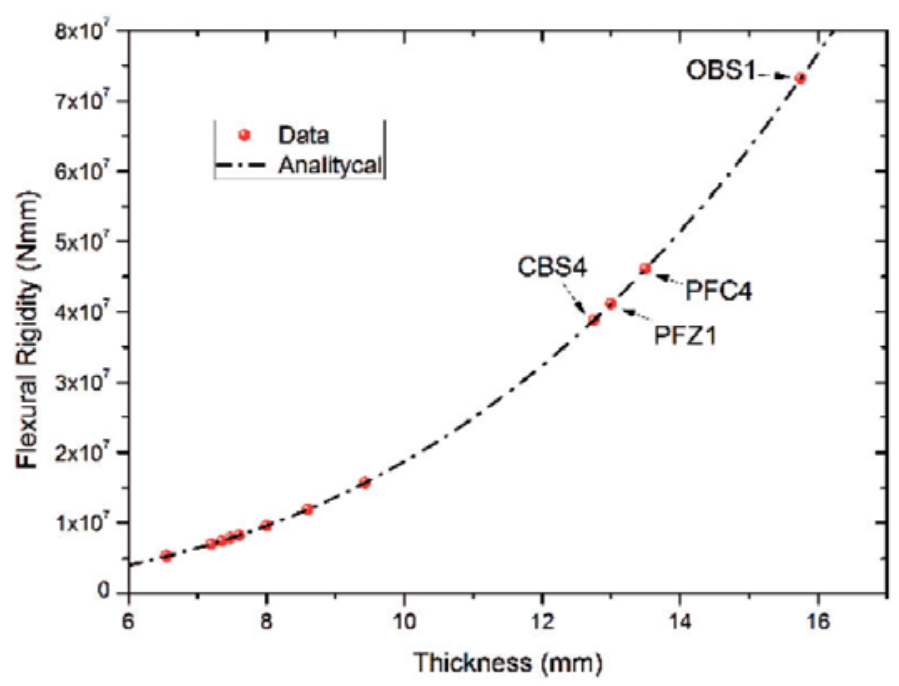

Figure 18: Correlation between Flexural rigidity D and Thickness

Combining the previous graph with the response surface shown in Figure 19 it can be seen that the higher values of the buckling load are reported at the values of the flexural rigidity of the four aforementioned cross sections.

On the basis of the previous considerations a single analytical approach cannot be identified to correlate the results with respect to the buckling response. However, for an open cross section it can be considered that at a thickness value greater than $12.75 \mathrm{~mm}$ the buckling is global whilst below this value the buckling is local. Considering the maximum bending stress values obtained using FE analysis, the response surface shown in Figure 20 correlates it with the I (Second moment 
of area) and the $D$ (Flexural rigidity). The cross sections for which the minimum values of the bending stress are attained are CBS2 CBS3 and CBS5, which actually are closed sections. As previously discussed before, the middle space between the beams should be accessible to fit a power convertor - is a crucial aspect for the design of the central beam of the wagon (Table 1). For this reason, 'open' sections are considered (i.e. those for which it is possible to access the space between the beams themselves). These sections (PFC3 CBS1 PFC1 PFC5 and PFZ1) have bending stress ranging between $38 \mathrm{MPa}$ and $48 \mathrm{MPa}$.

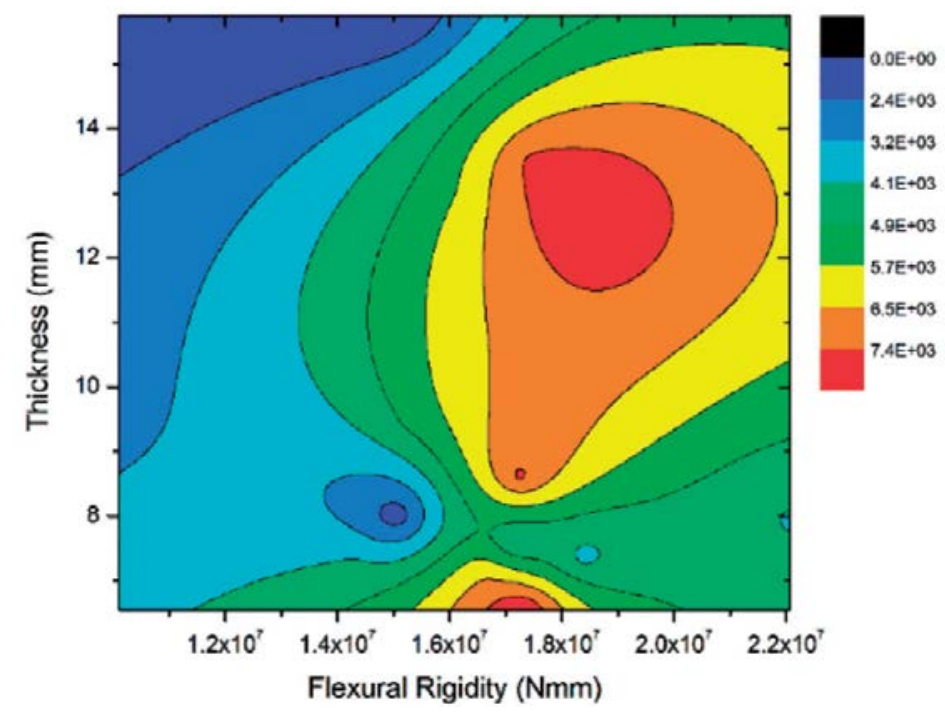

Figure 19: Surface response to correlate buckling load with thickness and flexural rigidity

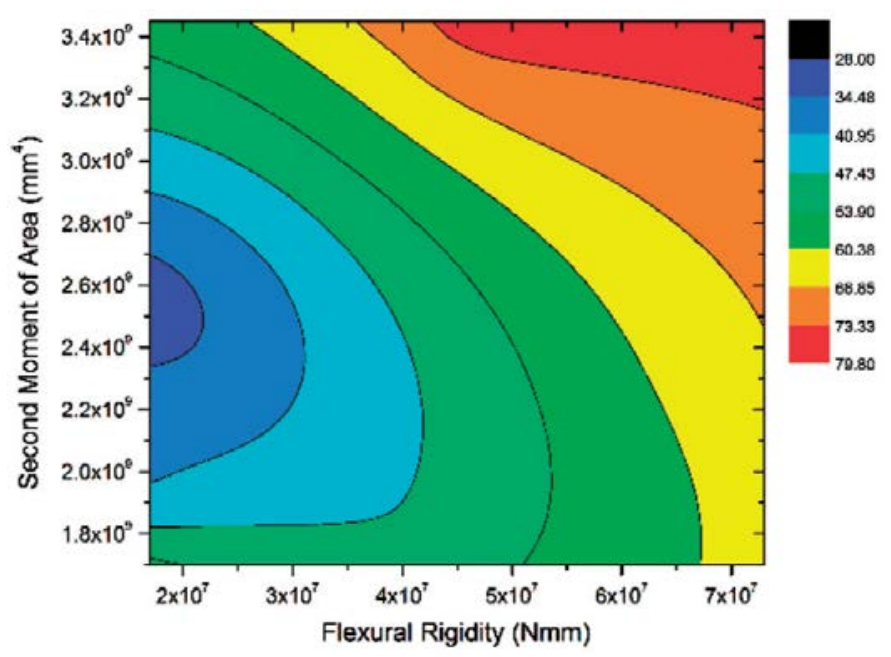

Figure 20: Surface response to correlate maximum stress with Second moment of area and flexural rigidity In terms of vertical displacement it is observed that an increase in the values of second moment of area together with the flexural rigidity increases the values of the vertical displacement due to an increase in the local stiffness which results in a greater displacement of the sections at the applied load (Figure 21). 


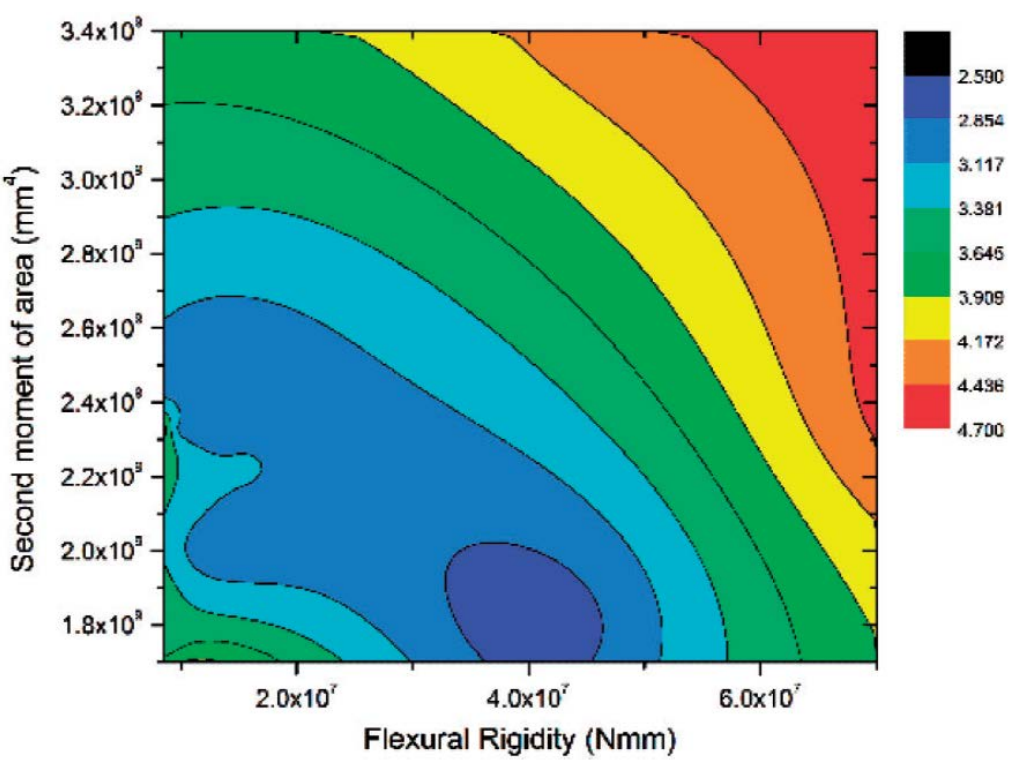

Figure 21: Surface response to correlate vertical deflection with Second moment of area and flexural rigidity

Regarding the response surface in which the vertical displacement is related to the bending stiffness and the second moment of area (Figure 22), it can be seen that the results are in agreement with the beam theory. For each value of the second moment of area the maximum vertical displacement is attained at the minimum value of the bending stiffness.

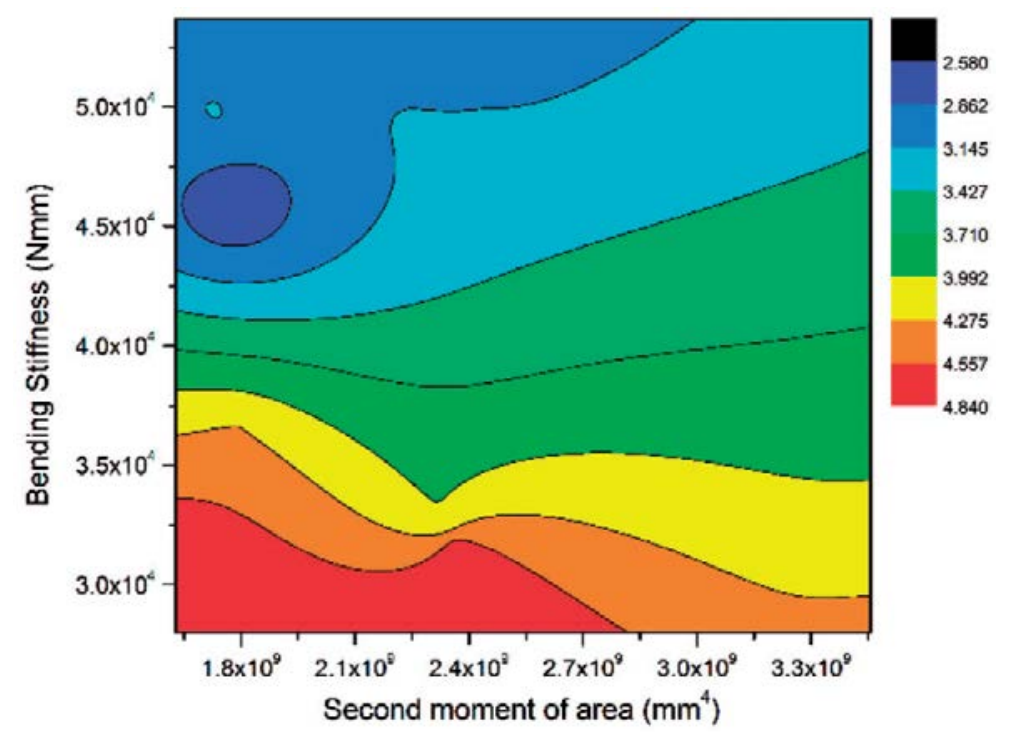

Figure 22: Surface response to correlate vertical deflection with bending stiffness and Second moment of area

The bending stiffness is a global property of the beam and does not take in account the local stiffness of the parts constituting the beam. Since the results discussed in the present paper are related to beams having the same values of the cross section area, modifying the thickness the 
value of vertical displacement increases or decreases depending on the concurrent effects produced by the local and the global stiffness of the beam. On the basis of the previous considerations, the value of the vertical displacement at a certain value of the bending stiffness increases as the flexural rigidity increases due to an increase in the local stiffness of the beam which results in a greater vertical displacement of the entire beam. Some of the beams under evaluation are composed of different parts connected together with spot-welds or welds, which affects the deformability as well as the maximum stress. Since the results discussed here are affected by these factors, the response surfaces present a different trend in the region with low values of the flexural rigidity and bending stiffness (Figure 23).

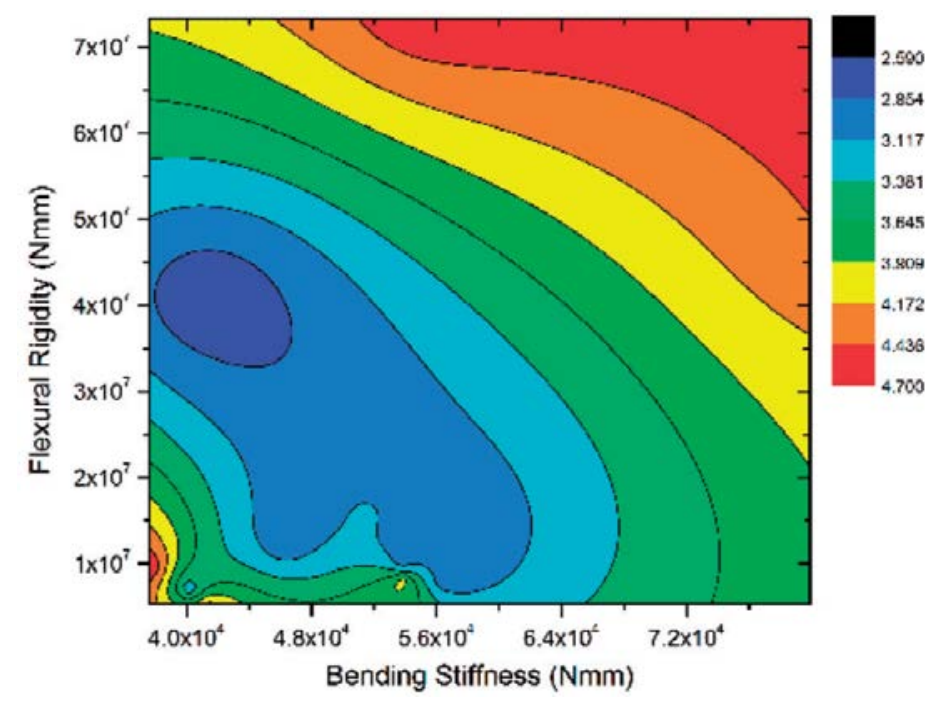

Figure 23: Surface response to correlate vertical deflection with bending stiffness and flexural rigidity

\subsection{CONCLUSIONS}

This paper has applied the conventional engineering design process to develop a framework specific to selecting the geometrical section profile of an intermodal freight wagon main beam. Various sections were considered including I, C, Z and derivative compound sections. Both ordinary (non-prefabricated) and pre-fabricated sections were considered. Out of 24 sections analysed for structural integrity, bearing in mind lightweighting as the main objective, scores indicate that overall the lipped Z (pre-fabricated) section is the preferred section. It is noteworthy that within the top 3 sections, two were pre-fabricated while the other one was an ordinary section. This shows that even though prefabricated sections have not been applied in construction of freight wagons, there exists high untapped potential for lightweighting the wagons. 
Further analysis was regarding the structural behaviour of the considered sections profiles. In particular, the possibility to implement a 3D model of each beam enabled proper understanding of the response of each beam in terms of stiffness and strength overcoming the limitations related to the theoretical beam theory. However, the response in terms of global stiffness is in accordance with the beam theory, since it is related to the overall structure, whilst the buckling and the vertical displacements, which are strongly affected by the local behaviour of the structure, differ from what predicted from the analytical approach. For the buckling conditions, it has been possible to identify a cut-off thickness $(t=12.75 \mathrm{~mm}$ ) at which the local buckling becomes global.

Regarding the maximum stress values, the possibility to model in details the welds allowed for accounting for stress concentration effects close to the welding locations and due to the variation in stiffness. By means of the detailed modelling approach more realistic values, rather than the nominal values identified with the beam theory, have been obtained. On the basis of the results presented in this paper, it can be deduced that the optimisation process, which relies on the results obtained using beam theory, has certain limitations. In particular, ignoring the effects related to the actual cross section on the local stiffness can lead to neglecting stress increase or local buckling phenomena, which can strongly affect the final results when the cross section is implemented in service.

\section{COMPLIANCE WITH ETHICAL STANDARDS:}

Funding: This study was funded by European Commission 7th Framework Program SPECTRUM Project Grant Agreement No 266192.

Conflict of Interest: The authors declare that they have no conflict of interest.

\section{REFERENCES}

1. Findik, F. and K. Turan, Materials selection for lighter wagon design with a weighted property index method. Materials \& Design, 2012. 37: p. 470-477

2. Lee, H.-A., et al., Structural-optimization-based design process for the body of a railway vehicle made from extruded aluminum panels. Proceedings of the Institution of Mechanical Engineers, Part F: Journal of Rail and Rapid Transit, 2016. 230(4): p. 1283-1296.

3. Prasad, K. and S. Chakraborty, A quality function deployment-based model for materials selection. Materials \& Design, 2013. 49: p. 525-535.

4. Farshi, B. and A. Alinia-Ziazi, Sizing optimization of truss structures by method of centers and force formulation. International Journal of Solids and Structures, 2010. 47(18): p. 2508-2524

5. Seo, Y.-D., H.-J. Kim, and S.-K. Youn, Shape optimization and its extension to topological design based on isogeometric analysis. International Journal of Solids and Structures, 2010. 47(11): p. $1618-1640$ 
6. Kim, Y.Y. and G.H. Yoon, Multi-resolution multi-scale topology optimization-a new paradigm. International Journal of Solids and Structures, 2000. 37(39): p. 5529-5559.

7. Kim, Y.Y. and T.S. Kim, Topology optimization of beam cross sections. International journal of solids and structures, 2000. 37(3): p. 477-493

8. Liu, J.-S. and T.J. Lu, Multi-objective and multi-loading optimization of ultralightweight truss materials. International Journal of Solids and Structures, 2004. 41(3): p. 619-635

9. Ashby, M.F. and D. Cebon, Materials selection in mechanical design. Le Journal de Physique IV, 1993. 3(C7): p. 1155-4339.

10. Ashby, M.F., Multi-objective optimization in material design and selection. Acta materialia, 2000. 48(1): p. 359-369.

11. Ashby, M.F., et al., Selection strategies for materials and processes. Materials \& Design, 2004. 25(1): p. 51-67

12. Karande, P., S.K. Gauri, and S. Chakraborty, Applications of utility concept and desirability function for materials selection. Materials \& Design, 2013. 45: p. 349-358.

13. Wright, I.C., Design methods in engineering and product design. 1998: McGraw-Hill.

14. Richardson, J.N., R.F. Coelho, and S. Adriaenssens, Robust topology optimization of truss structures with random loading and material properties: A multiobjective perspective. Computers \& Structures, 2015. 154: p. 41-47.

15. Seyfried, P., et al., Light weighting opportunities and material choice for commercial vehicle frame structures from a design point of view. Advances in Manufacturing, 2015. 3(1): p. 19-26

16. Polyzois, D. and P. Charnvarnichborikarn, Web-flange interaction in cold-formed steel Z-section columns. Journal of Structural Engineering, 1993. 119(9): p. 2607-2628.

17. Ghosn, A.A., Deflection of nested cold-formed steel Z-section beams. Journal of Structural Engineering, 2002. 128(11): p. 1423-1428

18. Ghosn, A.A. and R.R. Sinno, Load capacity of nested, laterally braced, cold-formed steel Z-section beams. Journal of Structural Engineering, 1996. 122(8): p. 968-971.

19. Alinia, M.M. and A. Dibaie, Buckling and failure characteristics of slender web l-column girders under interactive compression and shear. Computational Methods in Civil Engineering, 2012. 3(1): p. 15-34.

20. He, Z. and X. Zhou, Strength design curves and an effective width formula for cold-formed steel columns with distortional buckling. Thin-Walled Structures, 2014. 79: p. 62-70

21. Naderian, H.R. and H.R. Ronagh, Buckling analysis of thin-walled cold-formed steel structural members using complex finite strip method. Thin-Walled Structures, 2015. 90: p. 74-83

22. Hou, J. and G. Jeronimidis, A novel bogie design made of glass fibre reinforced plastic. Materials \& Design, 2012. 37: p. 1-7

23. Matsika E, O.N.C., Grasso M, De lorio A, Linde P, Jönsson R, van den Bold P Deliverable 3.1 Detailed Structural Design Concept for a High Performance Freight Wagon. EC SPECTRUM Project FP7 Grant Agreement No 266192, 2014.

24. Wennberg, D., S. Stichel, and P. Wennhage, Substitution of corrugated sheets in a railway vehicle's body structure by a multiple-requirement based selection process. Proceedings of the institution of mechanical engineers, Part F: journal of rail and rapid transit, 2012.

25. Wallentowitz, H., J. Leyers, and T. Parr, Materials for future automotive body structures. Business Briefing: Global Automotive Manufacturing \& Technology, 2003: p. 1-4.

26. D.A., V., Refining methods of calculating fatigue resistance in welded connections of the frames of long flat wagons. PhD thesis, 2010. Defended at Petersburg State Transport University(St. Petersburg): p. 115.

27. EC, EN 12663-2:2010 Railway Applications - Structural Requirements of Railway Vehicle Bodies. Part 2: Freight Wagons. 2010.

28. EC, EN 14363:2005 Railway applications - Testing for the acceptance of running characteristics of railway vehicles - Testing of running behaviour and stationary tests. 2005.

29. Ashby, M.F., Materials selection in mechanical design. MRS Bull, 2005. 30(12): p. 995. 